\title{
The Welding Processes of Rolled Homogeneous Armour Steel
}

\author{
N. Vimal Kumar, M. Uthayakumar, S. Thirumalai kumaran
}

\begin{abstract}
Rolled Homogeneous Armour (RHA) steel is known as protective steel and it is utilized in a military vehicle, For example tanks, howitzers, heavily clad battle vehicles just as developments in armament. Weld quality straight forwardly decides the entire mechanical properties of the protective steel in vehicle body structures. Hybrid Optical Maser Arc welding (HOMAW) has a decent mechanical property and focal point of this exploration is considered to recover more energy than laser and Metal Active Gas Welding (MAGW) process. Manual Metal Arc Welding (MMAW) with low hydrogen ferritic filler (LHF) which performs better weldability on Armour steels with comparing MMAW with Austenitic stainless steel (ASS), and Flux cored arc welding (FCAW) with ASS/LHF. MMAW procedure is considered to reduce the expense through LHF consumable in workplace. The examination of MAGW method, a welding fringe of $54^{\circ} \mathrm{V}$-narrow cut geometry has better mechanical property for tensile strength and also the welding narrow cut point of $48^{\circ}$ $X$-trench cut geometry has better solution for compression strength of butt-joint Armour steel. This survey was embraced to grant a top-level view of the various categories of welding process and mechanical properties in welding of RHA steels.
\end{abstract}

Keywords : Rolled homogeneous Armour steels, welding processes, mechanical properties.

\section{INTRODUCTION}

Q uenched (Q) and Tempered (T) Armour steel is known as RHA steel. The different composition and heat treatment of Q\&T Armour steels are intended to convey optimum mechanical properties as shown in Fig.1. Q and T Armour steels is also known as $\mathrm{Q}$ and $\mathrm{T}$ protective steel and it is promptly weldable utilizing customary arc welding forms. The additional consideration must be taken to stay away from both Hydrogen Assisted Cold Cracking (HACC) and relaxing in the warmth influenced zone (WIZ). By exchanging this system, it has distinctive process that prefers in welding systems. A few systems and a portion of their points of interest are depicted in the following section.

Revised Manuscript Received on December 30, 2019.

* Correspondence Author

N. Vimal Kumar, Department of Automobile Engineering, Kalasalingam Academy of Research and Education, Krishnankoil, Virudhunagar- 626126, Tamilnadu, India. Email: nvimalkumar1@gmail.com

M. Uthaya Kumar*, Faculty of Mechanical Engineering, Kalasalingam Academy of Research and Education, Krishnankoil, Virudhunagar- 626126, Tamilnadu, India. Email: uthaykumar@gmail.com

S. Thirumalai Kumaran, Faculty of Mechanical Engineering, Kalasalingam Academy of Research and Education, Krishnankoil, Virudhunagar- 626126, Tamilnadu, India. Email: thirumalaikumaran@yahoo.com

\section{A. RHA Steel}

The Armor steel is known as protective steel and it has lean composition which is easier for welding process. Defensive steels are high quality, hardness and great toughness. The steel procures these particular properties because of severe necessities on substance cleanness $(\mathrm{H}, \mathrm{N}, \mathrm{P}$ or $\mathrm{S}$ substance) and explicit creation process, finished by quick $\mathrm{Q}$ and $\mathrm{T}$. Defensive steels creation procedure comprises the couple of significant strides to achieve their essential mechanical properties. Initial step is continual casting of chunks with utilizing of mineral with high compound virtue. The following stage is rolling of the chunks at temperature about $1250^{\circ} \mathrm{C}$ to refine its microstructure - austenitic grains. At that point the sections are positioning the strengthened at temperature about $850^{\circ} \mathrm{C}$. The two most significant approaches are $\mathrm{Q}$ and $\mathrm{T}$. The chunks are extinguished in ceaseless heater from the temperature about $1000^{\circ} \mathrm{C}$ to solidify the steel and lastly low $\mathrm{T}$ at about $200^{\circ} \mathrm{C}$ so as to make the solidified steel harder. The substance cleanness in mix with fast cooling brings the great toughness of material regardless of $\mathrm{T}$ at exceptionally low temperatures. Because of these creation procedure points of interest; the fabricators prescribe don't surpass the temperature around $200^{\circ} \mathrm{C}$ during the auxiliary preparing of protective steels as in welding. If it exists $200^{\circ} \mathrm{C}$, in this situation rupture takes place on mechanical properties [13].

\section{B. Weldability of Armour Steel}

Various welding methods are utilized when welding Armour segments; along these lines any microstructural changes during creation are unacceptable. When the steel is exposed to welding, the area encompassing the weld pool known as WIZ, experiences complex thermal cycles which change unique microstructural of the material. The characteristics of the material depends on the nature and number of heat cycles changes, it may prompt undesired impacts such as WIZ mellowing (or solidifying) and HACC. To conserve unique properties of the steel plate, it is beneficial to utilize welding methods with optimized heat inputs and if conceivable, least number of the weld passes. 


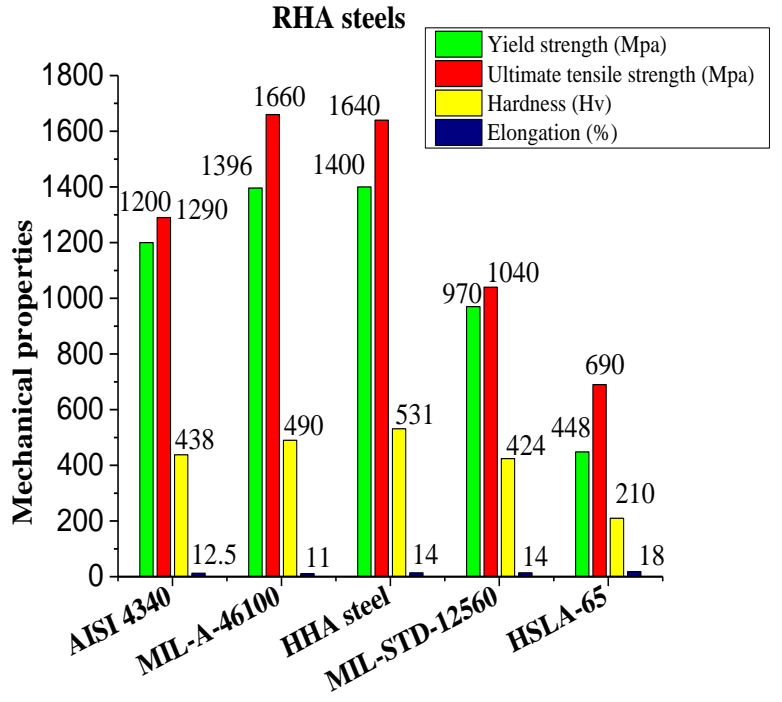

Fig. 1. Mechanical properties of RHA steel

\section{LITERATURE}

Sowards et al., [1] proposed a technique of Hybrid Optical Maser Arc welding (HOMAW) consolidates a laser warmth source with metal active gas welding warmth source to conquer a large number of the impediments experienced while utilizing either welding procedure without anyone else. These focal points incorporate expanded welding speed, the capacity to weld thicker materials; the capacity to effective bridge gaps when part fit-up is poor, superior weld quality, and more noteworthy steadiness of the welding procedure. Bragg fringe neutron transference imaging was utilized to clarify the spatial dispersion about thermally instigated remaining strains during a steel Armour plate welded with a hybrid optical maser arc welding. This residual strain conveyance was contrasted with the spatial advancement of mechanical strain during uniaxial disfigurement. By relating the strain estimations of the two strategies, the disappointment system was resolved in protection welds united with this procedure. Weld disappointment reliably happened in the subcritical heat-influenced zone, where mechanical strain aggregation in mellowed martensitic parent material was superimposed upon the weld area containing the most lingering thermally actuated strain.

Aleksandar Cabrilo et al., [2] proposed a technique on weldability of superior hardness protective steel by the metal active gas welding (MAGW) strategy had done. In this research, it is concluded that hand-operated welding contrasted with mechanized welding through microhardness measurement, cooling speed, tensile properties, and non-destructive investigation. It conducts the mechanized welding process on the impact energy, micro hardness in the combination lines and most receptive zone of welded protective steel. It is determined that preheating and interpose temperature was significant as far as the rate of cooling and presence of hydrogen in the weld joint. The elasticity obtained maximum value of $800 \mathrm{MPa}$. The area of the heat influenced zone did not surpass $15.9 \mathrm{~mm}$, estimated from origin of the weld, hence the impact energy is 74 and $39 \mathrm{~J}$ at $20{ }^{\circ} \mathrm{C}$ and $-40{ }^{\circ} \mathrm{C}$.

Cao et al., [3] presented Hybrid Optical Maser Arc welding (HOMAW) is a developing joint innovation that is favorable as scope for shipbuilding applications. The HOMAW joins the interdependent characteristics of the optical maser and MAG arc segment welding procedures. It allows a high energy density method with fit-up hole resistance. The warmth contribution of HOMAW is more prominent than in optical maser welding, yet a lot littler than in metal active gas arc welding, a generally thin weld and limited WIZ was obtained. It can limit the residual stress and malformation. Besides, including metal active gas arc can expand the infiltration base for a given laser control. It means higher rate of welding or a smaller amount of passes fundamental for thicker plates of single-sided welding. In this process, another Hybrid Optical Maser Arc welding framework has effectively connected to completely infiltrate butt joints of $9.3 \mathrm{~mm}$ thickness utilizing a one-sided pass method through streamlining of the trench shape, size and preparing guidelines.

Shuangyu Liu et al., [4] proposed about the impacts of arc and optical maser arrangement on weld respectability for the HOMAW forms. A $4000 \mathrm{KW} \mathrm{Nd:} \mathrm{YAG} \mathrm{laser} \mathrm{and} \mathrm{a} \mathrm{metal}$ inert gas welding facility were used for investigating high quality steel utilization under two designs of hybrid arcoptical maser welding (HAOMW) and HOMAW. Mechanical measurement and Metallographic investigation were accomplished to assess the weld honesty as far as the geometry of weld bead, mechanical properties and microstructure. The structure of the weld bead area was considered and the distinctive macrostructure of the weld beads gave off an impression of being cone geometry and cup geometry under HAOMW and HOMAW designs, individually. The weld honesty qualities of microstructure, stage elements and microhardness has been investigated for various weld fields. The malleable and effect tests were accomplished and cracking surface structure was examined by Scanning Electron Microscope (SEM) instrument. The investigation demonstrated that HAOMW delivered joints with a superior weld shape and a progressively uniform microstructure of slat martensite, While HOMAW weld had a heterogeneous structure of strip martensite and austenite.

Lenka Kuzmikova, [5] investigated an enhancement of flux cored arc welding (FCAW) method, alteration of the system for completely robotized welding in mix with metal-cored consumable and lastly appraisal of attainability. Hybrid welding utilizes strong consumable for potential future substitution of the present procedure. The destinations of this work have been accomplished bringing about enhanced welding methodology for high hardness Armour (HHA) steel. Also, from the whole group of high-quality Q\&T steels HHA has a most astounding carbon content, carbon equivalent, hardenability and in this manner. It is the hardest to weld henceforth the discoveries of this exploration work can be connected to all high-quality $\mathrm{Q}$ and $\mathrm{T}$ steels. Further, the proposed methodology dependent on the distinction in change temperature of weld metal and WIZ can be utilized as an effective tool for future evaluation of hydrogen control in steel welding.

Nazli Ezgi Ipek et al., [6] proposed a strategy for essential purpose behind the broad 
utilization of Q and T steel in combat applications and other comparative combat vehicles are Armour properties, for example, sufficient quality, great weldability, high strength, and it's cheaper assembling price contrasted with similar protection materials. Hence examination was analyzing the impacts of welding point and geometry on mechanical properties, for example, strain, pressure, and bowing quality of butt-joint protective layer steel. Armour steel plates was readied utilizing $\mathrm{X}, \mathrm{V}$ grade welding techniques and three distinct sorts on score edges, and these was joined through metal active gas welding (MAGW) technique. The impacts of welding guidelines are welding trench geometry and welding notch edge on pressure and bowing quality have additionally been concentrated numerically utilizing finite element analysis (FEA). Accordingly, a welding edge of $54^{\circ}$ and V-trench geometry was observed to be the improved mechanical properties for strain quality. Also, welding notch edge of $48^{\circ}$ and $\mathrm{X}$-trench geometry was observed that the best answer for compression quality is butt-joint welded Armour steel.

Balakrishnan et al., [7] presented that Rolled Homogeneous Armour (RHA) steel firmly affirming to AISI 4340 is notable to predominant missile exhibition and consequently utilized creation on Armour vehicles. The protective steels are customarily bonded by austenitic stainless steel (ASS) filler in MMAW to avoid hydrogen convince fracture. Due to weld heat revolution and below coordinating fillers, the protective steel joints show deficient missile execution contrasted with the protective steel. Despite of this strategy, yielded minor enhancements in ballistic execution, breaks were seen in the middle of protective metal and hardfaced layer. Hence the examination on endeavour made to take out these breaks on saving a delicate buttering on the layer utilizing ASS consumable in the middle of protective metal and hardfaced layer. In this paper, it uncovers the impact of buttering and hardfacing layer on missile execution of MMAW protective steel joints.

Grujicic et al. [8] investigated to create multi-material science mathematical model for traditional MAGW procedure has enhanced on its prescient capacities in regarding to spatial dissemination of the mechanical properties (quality specifically) inside the weld. The enhanced MAGW method is next connected to instance on butt-welding of MIL A46100 (a prototypical superior-hardness Armour grade martensitic steel) material utilizing filler metal terminals construct a similar Armour grade. A basic evaluation directed to essential establishment on the prototype, including on five modules. It is individually devoted to deal with a particular part of the MAGW procedure, for example, (i) electro-elements on welding-gun, (ii) radiation/convection-controlled warmth move together from the electric arc segment to the base material and mass exchange from the filler-metal consumable to weld, (iii) the forecast advancement and the spatial conveyance on mechanical fields on the weld locate during the MAGW process, (iv) the subsequent temporary development and spatial circulation on the material microstructure through weld district and (v) spatial dissemination on as-weld material in mechanical properties. Related to spatial conveyance forecasts of MAGW model has enhanced in the material microstructure and properties, it is observed and predictable in MIL A46100 butt-weld general desires and earlier perceptions. To clarify microstructure/property connections inside various bits of the weld, progressed physical-metallurgy ideas and standards are recognized, and their administering condition guidelines connected inside a post-preparing information decrease technique.

Cabrilo et al., [9] found that welding of protective steel is intricate by the maximum level of carbon in the protective metal, due to presence of flaws as breaks and pores that formed during weld metal and WIZ. The break framed in protective metal or WIZ, because of active or effect loads, can simply pursue on propagate to combination line, after its quickened development happens. It exhibits the choice of the preheating and interpose temperature was significant as far as the rate of cooling and presence of hydrogen in the weld joint The critical method for evaluating the resist the material to inception, proliferation of cracks and impact energy was estimated with instrumented pendulum in the zone of base metal, weld metal and WIZ, at temperatures of $-40^{\circ} \mathrm{C},-20^{\circ} \mathrm{C}$, $0^{\circ} \mathrm{C}$ and $20^{\circ} \mathrm{C}$. The impact energy analyzed by demonstrating high energy at beginning, the crack spreads in weld metal and WIZ zones, while the most reduced energy was in the base metal.

Babu et al., [10] examined depicts about enhancing the ballistic resistance of protective steel joints which are manufactured by combining of plasma transferred arc (PTA) hardfaced interlayers in the middle of delicate ASS welds. From the outcomes, the welds with combined interlayer which halts every one of the shots effectively, independent of procedures utilized, though welds without combined interlayer were fizzled. To know the reason for disappointment, a complete metallographic experimental study was done. The varieties of microstructure and hardness at different zones of the weld are suggest about because, it was discovered that the Armour steel could be hardfaced on the PTA procedure with tungsten carbide powder. From this examination, it is discovered that the bond created with hardfaced interlayer displayed a most extreme upgrade in missile point of confinement of about 5.25 occasions more than that of the bond manufactured without interlayers.

\section{METHODS}

A number of welding techniques are used to welding Armour components in combat vehicles. Q \& T protective steels are readily weld able using conventional arc welding processes. Although, Additional care must be taken to avoid both HACC and softening of the WIZ. Trade-offs do exist and different welding techniques offer advantages in different areas. Several techniques and some of their advantages are described in the following section.

\section{A. Hybrid Optical Maser Arc Welding (HOMAW)}

The hybrid which uses collaboration between optical maser and welding arc segment can possibly offer the perfect answer for welding high quality protective steels.

It couples the advantages and to a great extent overcomes the impediments of the two individual

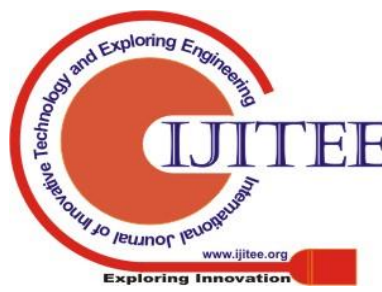




\section{The welding processes of rolled homogeneous Armour steel}

procedures. During HOMAW process a littler weld pool is shaped in correlation with the FCAW strategy. This results in lower warmth input and thus a smaller WIZ. The WIZ hardness of laser welded area (in laser welding alone has high hardness and has expanded weakness to HACC) is tempered by consequent MAGW pass. The WIZ properties can be additionally improved by decrease of weld passes what might likewise prompt critical time and cost investment funds. Also, cross breed optical maser-MAGW process in uses solid ASS consumable that as per information from weld hydrogen testing results in zero weld diffusible hydrogen content, for all intents and purposes precluding the danger of HACC, normal imperfection experienced when welding high quality protective steels. Great Quality hybrid optical maser-MAGW welds can be created using different protecting gas arrangement ranges. It has been accounted for that I-butt and T-butt C-Mn steel joints with ideal quality were delivered using blend containing $40-50 \%$ of Helium $(\mathrm{He})$ and $2-5 \%$ of carbon dioxide $\left(\mathrm{CO}_{2}\right)$ in Argon (Ar). In any case, guarantee that protecting gas blends containing 30-40\% He are the most advantageous for both the laser and MAGW part and augmentations of above $40 \%$ He produce insecure welding arc segment. The warmth input from the welding arc is calculated by Equation (1) and (2).

$\mathrm{Q}_{\mathrm{a}}=((\mathrm{AxVx60)} /(\mathrm{Sx} 1000)) \mathrm{x}$ arc proficiency

$\mathrm{Q}_{\mathrm{I}}=(\mathrm{W} x 60) / \mathrm{S}$

From the weld arc, the warmth input $\mathrm{Q}_{\mathrm{a}}(\mathrm{KJ} / \mathrm{mm})$ is determined as pursues: Here $\mathrm{S}$ is travel speed $(\mathrm{mm} / \mathrm{min}), \mathrm{V}$ is voltage $(\mathrm{V})$ and $\mathrm{A}$ is current $(\mathrm{A})$. The curve proficiency factor obtained as 0.84 from metal active gas welding procedure. The ostensible warmth contribution from the laser bar $\mathrm{Q}_{\text {I }}$ can be acquired from the accompanying condition. Where $\mathrm{W}$ is the laser control.

\section{B. Optical Maser Welding (OMW)}

The required profound entrance could be accomplished by utilizing the optical maser welding process. The optical maser welding alone isn't the most reasonable choice for welding of high-quality protective steels in a creation situation. While it is a high efficiency low warmth information process, it produces narrow warmth influenced zones and steep spatial and transient temperature inclinations that frequently result in fragile microstructures vulnerable to HACC. Laser welding additionally creates welds with a high proportion between welding profundity and seam width. It results in a thin weld seam and a poor hole connecting limit. Because of this phenomenon, laser shaft welding requires high accuracy during edge readiness and set-up [5].

\section{Metal Active Gas Welding (MAGW)}

The generally high warmth contribution of the MAGW procedure results from the essentially lower energy density of the arc segment with a bigger concentrated spot on the material surface. This outcomes in diminished cooling rates, a wide WIZ regularly with improved flexibility (it ought to be noticed that for improved ballistic execution of welded segments, the WIZ ought to be kept as limited as would be acceptable). Another impediment of high warmth info procedure is that is can cause unwanted distortion and additionally buckling especially when welding lean plate. Welding of thicker plates quite often requires numerous goes as the character of the MAGW method counteracts profound entrance, since the infiltration profundity is an element of the warmth conduction. Welding of thicker areas with one pass would be conceivable by utilizing low welding velocities, bringing about considerably higher warmth input and unsatisfactorily wide and delicate WIZ and expanded danger of buckling and distortion [5]

\section{Manual Metal Arc Welding (MMAW)}

Protective steel firmly affirming to AISI 4340 is notable for its unrivalled missile exhibition and subsequently utilized in the manufacture of combat cars. These steels are generally welded by MMAW through ASS consumable to avert hydrogen convince fracture. The weld warm cycles and under coordinating fillers, the covering steel joints show poor ballistic execution contrast with the base metal. In this reason distinctive filler materials are utilized to counteract the poor missile exhibition, low hydrogen ferritic (LHF), high nickel steel (HNS). The joints created utilizing LHF steel cathodes demonstrated prevalent transverse malleable properties than different bonds. This bond created utilizing HNS terminals showed preferable impact properties over dissimilar joints. This joint manufactured by LHF steel cathodes showed lesser level of WIZ relaxing, while HNS weld displayed the most extreme WIZ mellowing because of the distinction in weld warm revolution.

\section{Flux Cored Arc Welding (FCAW)}

FCAW is a generally utilized manufacture system for joining high quality protective steel plates. The disadvantage of utilizing Flux-cored wires is that in multi-pass welding the slag framed on the surface of the bead needs should be removed before statement of subsequent passes, this is incapable regarding both efficiency and cost. In addition, the motion likewise can possibly get hydrogen from the encompassing climate if the consumable is put away improperly or over a significant lot of time. The hydrogen might be invested in the weld pool, expanding the danger of HACC. Welding of thicker plates quite often requires various goes as the FCAW produce gives generally low infiltration, the seam profundity being an element of the warmth conduction. Welding of thicker segments with one pass would be conceivable by utilizing slower welding paces, yet these would result in much higher warmth input and unacceptably wide and delicate WIZ. The Mechanical properties of HSLA protective steel in different welding process with appropriate consumables are appeared in Table I.

\section{DESIGN OF EXPERIMENTS}

RHA (Protective) steels are generally applied in the development of combat vehicles because of elevated strength to weight proportion and peak hardness. The protective steels are vulnerable to hydrogen convince fracture $(\mathrm{HCF})$ in the WIZ subsequent to welding.

The utilization of ASS filler used to weld the mentioned steel and the main accessible cure due to higher dissolvability for hydrogen in austenitic stage.

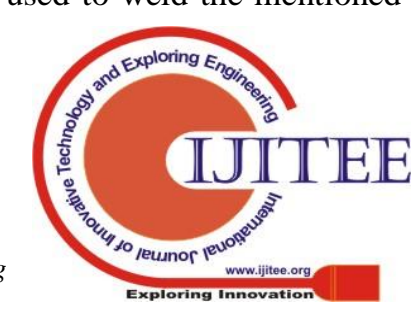


International Journal of Innovative Technology and Exploring Engineering (IJITEE) ISSN: 2278-3075, Volume-9, Issue-2S2, December 2019

Table I: Mechanical properties of welded Armour steels in different welding process

\begin{tabular}{|c|c|c|c|c|c|c|c|c|c|}
\hline \multirow{3}{*}{$\begin{array}{l}\text { Sl. } \\
\text { No }\end{array}$} & \multicolumn{9}{|c|}{ Mechanical properties of welded Armour steel } \\
\hline & \multirow[b]{2}{*}{$\begin{array}{l}\text { Welding } \\
\text { process }\end{array}$} & \multirow[b]{2}{*}{$\begin{array}{l}\text { Armour grade and } \\
\text { consumables }\end{array}$} & \multirow[b]{2}{*}{$\begin{array}{l}\text { Yield } \\
\text { strength } \\
(\text { Mpa })\end{array}$} & \multirow{2}{*}{$\begin{array}{l}\text { Ultimate } \\
\text { tensile } \\
\text { strength } \\
\text { (Mpa) }\end{array}$} & \multirow[b]{2}{*}{$\begin{array}{l}\text { Elongation } \\
(\%)\end{array}$} & \multicolumn{3}{|c|}{ HAZ Hardness $(\mathrm{Hv})$} & \multirow[b]{2}{*}{$\begin{array}{l}\text { Joint } \\
\text { efficiency } \\
\text { (\%) }\end{array}$} \\
\hline & & & & & & $\begin{array}{l}\text { Weld metal } \\
\text { region }\end{array}$ & $\begin{array}{l}\text { HAZ } \\
\text { region }\end{array}$ & $\begin{array}{l}\text { Base metal } \\
\text { region }\end{array}$ & \\
\hline 1 & SMAW & $\begin{array}{l}\text { AISI } 4340 \text { grade \& } \\
\text { AWS E307 (ASS) }\end{array}$ & 620 & 650 & 6.25 & 261 & 437 & 456 & 50 \\
\hline 2 & SMAW & $\begin{array}{l}\text { AISI } 4340 \text { grade \& } \\
\text { AWS E11018-M (LHF) }\end{array}$ & 830 & 860 & 10.00 & 311 & 443 & 457 & 66 \\
\hline 3 & FCAW & $\begin{array}{l}\text { AISI } 4340 \text { grade \& } \\
\text { (AWS E307) T1-1 } \\
\text { (ASS) }\end{array}$ & 529 & 571 & 5.00 & 245 & 424 & 453 & 44 \\
\hline 4 & FCAW & $\begin{array}{l}\text { AISI } 4340 \text { grade \& } \\
\text { AWS E110T5-K4 } \\
\text { (LHF) }\end{array}$ & 780 & 810 & 8.75 & 294 & 427 & 457 & 62 \\
\hline 5 & GMAW & Protac 500 \& ER 307 & 552 & 833 & - & 339 & 521 & 589 & - \\
\hline 6 & GMAW & $\begin{array}{l}\text { MIL-STD-12560 \& } \\
\text { AWS A5.10, MIL-100s }\end{array}$ & 805.9 & 688.3 & 22.4 & - & - & - & - \\
\hline
\end{tabular}

The utilization of stainless steel filler for a non-treated steel base metal isn't affordable. Consequently, interchange fillers for welding protective steels and their defencelessness to $\mathrm{HCF}$ should be investigated. Ongoing investigations demonstrated that LHF steel filler can be utilized to weld protective steels, which can give low level of hydrogen in the weld stores. The utilization of ASS and LHF fillers will prompt particular microstructures in them separate welds. MMAW and Flux cored arc welding (FCAW) were utilized for creation of joints utilizing ASS and LHF fillers. The weld created by SMAW procedure utilizing LHF filler displayed prevalent fatigue crack growth resist than every other joint [11].

Optical maser welding alone isn't the most reasonable choice for welding of Armour combinations. It is a high efficiency low warmth information process which creates a narrow WIZ steep spatial and worldly angles which may result in weak microstructures, and this does not support ballistic execution. The generally high warmth contribution of the MAGW procedure results from the altogether lower energy density of the arc with a bigger concentrated spot on the material surface. The results in decreased cooling rates, a wide WIZ frequently with improved elasticity (it ought to be noticed that for improved ballistic execution of welded parts, the WIZ ought to be kept as narrow as would be feasible). Another weakness of high warmth info procedure is that it can cause unfortunate distortion as well as buckling especially when welding lean plate.

The microstructure of HAOMW was comprised of strip martensite and described from 404 to $480 \mathrm{Hv}$ by extending its high hardness. The microstructure of hybrid optical maser arc welding HOMAW had the heterogeneous structure of strip martensite and austenite. The HAOMW microstructure of the arc zone was made out of strip martensite and portrayed high hardness from 420 to $480 \mathrm{Hv}$. The HOMAW microhardness of laser zone was made from austenite and strip martensite was described with a low hardness extending from 190 to 370 Hv [4]. In tanks and comparative military vehicles, tension, compression and bending stresses may happen in the meantime or separately. The choice of welding groove point and geometry ought to be resolved by area and predominant stacking type to which the military vehicles will be uncovered. Based on the trial results that are upheld with the numerical outcomes in MAGW process, the welded joints of protective steel with $\mathrm{V}$ trench geometry and $54^{\circ}$ section point and welded examples with $\mathrm{X}$ joint plan and $48^{\circ}$ fringe is the best in having the most astounding quality in tensile strength and compressive strength separately [6].

An inventive hybrid optical maser-arc welding system has been created for $25 \mathrm{~mm}$ thick steel plates of single pass welding. The welded parts were built into a butt joint setup with a square notch of $2.5 \mathrm{~mm}$ air gap. Deformity free joints with satisfactory combination zone profile and great mechanical properties were effectively created [12].

\section{CONCLUSION}

The hybrid optical maser-MAGW welding strategy, consolidating laser welding with MAGW, can possibly accomplish much quicker welding speeds than optical maser welding itself along these lines improving profitability. The filler material of the MAGW procedure can be chosen to create improved WIZ properties. The hybrid optical maser-MAGW procedure gets its advantages from the synergic impact of the optical maser and the arc segment. The elasticity, better weld state of HAOMW was higher than HOMAW. The impact energy and WIZ of HOMAW is more prominent than HAOMW.

From this examination, it is discovered that the joints created utilizing MMAW with low hydrogen ferritic consumables in protective steels demonstrated best weld metal in ferrite microstructure district alongside higher elasticity, more noteworthy weld metal hardness and unrivaled fatigue failure development opposition than MMAW with ASS and FCAW with ASS/LHF. The LHF fillers are suited to welding protective steel joints and in this manner clears route for cost effectual manufacture of compact vehicles.Weld joints of Armour shows the poor ballistic performance than base metal. ASS consumable has a good property to avoid the hydrogen induced cracking. Protective steel welding through MMAW with ASS filler is succeed in ballistic performance by using a buttering/hardfacing in between joining of two Armour metals.

The welded joints with $\mathrm{V}$ configuration have higher quality than the welded joints with $\mathrm{X}$ configuration within the sight of tensile strength in protective steel.

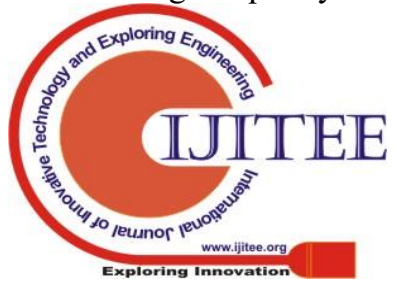




\section{The welding processes of rolled homogeneous Armour steel}

The welded joints with $\mathrm{X}$ configuration have higher quality than the welded joints with $\mathrm{V}$ configuration within the sight of compressive strength in protective steel by using MAGW process.

\section{ACKNOWLEDGMENT}

The authors submit their thanks to Combat Vehicles Research and Development Establishment (CVRDE), Avadi, Chennai for providing financial support to carry out this work (CVRDE/19CR0002/WKS/18-19/LT dated 10/8/18).

\section{REFERENCES}

1. J. W. Sowards, D. S. Hussey, D. L. Jacobson, S. Ream, and P. Williams, "Correlation of Neutron-Based Strain Imaging and Mechanical Behavior of Armour Arc Welding Process," Journal of Research of the National Institute of Standards and Technology, vol. 123, 2018, pp. 1-8.

2. A. Cabrilo, K. Geric, M. Jovanovic, and L. Vukic, "Weldability and Impact Energy Properties of High-Hardness Armour Steel," Journal of Materials Engineering and Performance, vol. 27, no. 3, 2018, pp. 1281-1295.

3. X. Cao, P. Wanjara, J. Huang, C. Munro, and A. Nolting, "Hybrid fiber laser - Arc welding of thick section high strength low alloy steel," Materials \& Design, vol. 32, no. 6, 2011, pp. 3399-3413.

4. S. Liu, Y. Li, F. Liu, H. Zhang, and H. Ding, "Effects of relative positioning of energy sources on weld integrity for hybrid laser arc welding," Optics and Lasers in Engineering, vol. 81, 2011, pp. 87-96.

5. L. Kuzmikova, "An Investigation of the weldability of high hardness Armour steels," 2013.

6. P. Taylor, N. E. İ, and F. Elaldi, "Analysis of Welding Groove Angle and Geometry on Strength of Armour Steel," Materials and Manufacturing Processes, vol. 27, no. 12, 2012, pp. 1437-1441.

7. M. Balakrishnan, V. Balasubramanian, G. M. Reddy, and K. Sivakumar, "Effect of buttering and hardfacing on ballistic performance of shielded metal arc welded Armour steel joints," Materials \& Design, vol. 32, no. 2, 2011, pp. 469-479.

8. M. Grujicic, S. Ramaswami, J. S. Snipes, R. Yavari, C-F. Yen, and B. A. Cheeseman, "Optimization of Gas Metal Arc Welding (GMAW) Process for Maximum Ballistic Limit in MIL A46100 Steel Welded All-Metal Armour," Journal of Materials Engineering and Performance, vol. 24, no. 1, 2015, pp. 229-244.

9. A. Cabrilo, "Impact energy properties of weld joint of high-hardness Armour steel," Advanced Technologies \& Materials, vol. 43, no. 1, 2018, pp. 11-16.

10. S. Babu, V. Balasubramanian, G. M. Reddy, and T. S. Balasubramanian, "Improving the ballistic immunity of Armour steel weldments by plasma transferred arc ( PTA ) hardfacing," Materials \& Design, vol. 31, no. 5, 2010, pp. 2664-2669.

11. G. Magudeeswaran, V. Balasubramanian, and G. M. Reddy, "Effect of welding processes and consumables on fatigue crack growth behaviour of armour grade quenched and tempered steel joints," Defence Technology, vol. 10, no. 1, 2014, pp. 47-59.

12. M. Wahba, M. Mizutani, and S. Katayama, "Single pass hybrid laser-arc welding of $25 \mathrm{~mm}$ thick square groove butt joints," Materials \& Design, vol. 97, 2016, pp. 1-6.

13. I. BARÉNYI, "Degradation of mechanical properties of selected UHSS steels in HAZ after their welding," Laser, vol. 1392, 2014, pp. 68.

\section{AUTHORS PROFILE}

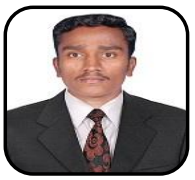

N. Vimal Kumar is currently a full time Research Scholar in Kalasalingam Academy of Research and Education, Krishnankoil, Virudhunagar-626126, Tamilnadu, India. He received M.E., degree from Thiagarajar College of Engineering (Autonomous), Madurai-625015, Tamilnadu, India. His research interests include welding and material characterization.

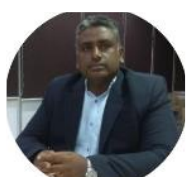

M. Uthayakumar completed his Doctoral work in the area of Precision Machining. He is actively working in the development of high strength light weight composites. His other areas of interest include processing of metal matrix, polymer matrix, ceramic matrix composite and its performance studies.

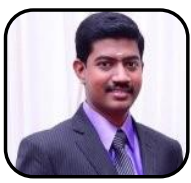

S. Thirumalai Kumaran completed his Ph.D. degree in Mechanical Engineering from Kalasalingam Academy of Research and Education (KARE), India, in 2015. After completing Ph.D., he worked as an Assistant Professor at School of Mechanical Engineering, Yeungnam University, South Korea for a period of one year. He is currently an Associate Professor at School of Automotive and Mechanical Engineering, KARE. 